\title{
Laboratory and Field Test of Movable Conduction-Cooled High Temperature SMES for Power System Stability Enhancement
}

\author{
Jiakun Fang, Jinyu Wen, Shaorong Wang, Jing Shi, Li Ren, Yuejin Tang, Xiaotao Peng, Zhe Chen
}

\begin{abstract}
This paper introduces the first movable conductioncooled high temperature superconducting magnetic energy storage (SMES) system developed in China. The SMES is rated at $380 \mathrm{~V} / 35 \mathrm{~kJ} / 7 \mathrm{~kW}$, consisting of the high temperature magnet confined in a dewar, the cryogenic unit, the converter, the monitoring and control unit, and the container, etc. The proposed SMES can be loaded onto a truck to move to a desired location and put into operation with easy connection. Laboratory and field tests have been carried out to investigate the operational characteristics and to demonstrate the SMES' effectiveness on improvements of system voltage stability and on the oscillation damping. Test results indicate that the SMES system has the features of fast response and four-quadrant power operation. The accessories for the movability of the SMES system are well designed. The system is feasible to be used in power systems.
\end{abstract}

Index Terms-- conduction cool, high temperature superconducting, moveable SMES, power system transient stability, superconducting magnetic energy storage

\section{INTRODUCTION}

A power system stabilizer based on energy storage system, as a potential solution to mitigate fluctuations of power generation and consumption and improve power system stability, draws much attention, especially under the situation of increasing penetration of the intermittent renewable power generations. Superconducting magnetic energy storage (SMES), featured with high efficiency, high power density and fast response, is a potential solution of dealing with power imbalance in a power system, enhancing stability [1]-[3] and improving power quality [4], [5].

In 1982-83, a 30MJ SMES was installed in the Bonneville Power Administration (BPA) Tacoma substation to mitigate the power fluctuations of the Pacific ac Intertie [6]-[9]. The SMES was also participates in voltage stability enhancement and frequency control. In 2000, the American Superconductor Corporation (ASC) and General Electric (GE) have developed the distributed SMES to improve voltage stability and system reliability [10]. The above mentioned SMES systems adopt low-temperature superconductors (LTS). The LTS require a working environment at $4.3 \mathrm{~K}$, and hence need supplementary

This work is supported by: National Natural Science Foundation of China (50937002) and the National HI-Tech R\&D Program of China (2011AA05A112).

Jiakun Fang, Jinyu Wen, Shaorong Wang, Jing Shi, Li Ren, Yuejin Tang, Xiaotao Peng are with the college of EEE, Huazhong University of Science and Technology, Wuhan, P. R. China.

Jiakun Fang and Zhe Chen are with department of energy technology, Aalborg University, Aalborg, Denmark. coolant such as liquid helium to be refilled continuously.

Compared to the LTS, the high-temperature superconductors (HTS) can achieve superconducting with transition temperature as high as $138 \mathrm{~K}$. SMES with HTS has the advantages of easier operation and more compact size. The efficiency of the cryogen increases exponentially with the temperature. Some projects have been conducted to use this type of SMES in power system applications [11]-[14]. The New Energy and Industrial Technology Development Organization (NEDO), cooperating with the Tokyo Electric Power Company and Kyushu Electric Power, proposed the commercial HTS SMES systems for stability enhancement (15 $\mathrm{kWh} / 100 \mathrm{MW})$ and load frequency control (500 kWh / 100 MW) [15], [16]. The beneficial role of SMES coil in HVDC lines as an energy buffer for renewable energy integration has been demonstrated in [17] and a 600 MWh SMES-HVDC project is under planning [18]. With the development in cryogenic technology, an HTS magnet can be cooled by a cryo-cooler directly without the need of liquid helium and nitrogen [19]. Since continuous refill of liquid helium or nitrogen is not necessary, the SMES with conduction cooling method can be built as a movable device. Such a movable SMES is proposed in [20] for power quality improvement. But few work about SMES with HTS magnets for improving transient stability has been reported.

This paper developed a movable SMES module converted from the laboratorial prototype proposed in [21]. All subsystems of the SMES are integrated into a portable module for transportation. As the first step to develop a movable high temperature conduction-cooled SMES for industry application, a series of laboratorial experiments as well as field experiments are carried out, including power regulation, and active and reactive power compensation. Functions of the SMES, including energy storage and stability enhancement, are demonstrated. The SMES is also used as the prototype for allocation and control strategy study.

The remainder of the paper is organized as follows: Section II introduces the structure and components of the SMES. Then in Section III, laboratory experimental results are presented to verify the functionality of each part of the SMES. The field test results are introduced in Section IV. Finally conclusions are drawn in Section V.

\section{DEVELOPMENT OF THE SMES}

The proposed SMES is rated at $380 \mathrm{~V} / 35 \mathrm{~kJ} / 7 \mathrm{~kW}$, consisting of the HTS confined in the dewar, the cryogenic unit, the converter, the monitoring and control unit (MCU), 
the container and other accessories. The system structure is shown in Fig. 1. The MCU is used to monitor the real-time operation conditions of both the SMES and the connected power system. Instructions are sent to the converter according to the controller embedded in the MCU. It also has the function of human-machine interface and waveform recording. The converter, as the electrical interface between the superconducting magnet and the power system, controls the dual-directional power flow between the ac and dc sides according to the instructions from the MCU. The solenoid type HTS of the SMES is confined in the dewar to be kept at low temperature by the cryogenic unit.

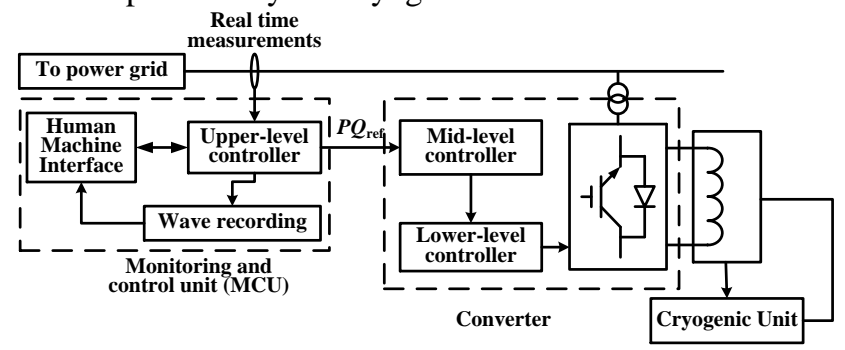

Fig. 1. Functional block diagram of the SMES

There are 3 control levels in the SMES system: one implemented in the MCU and the other two embedded in the converters shown in Fig. 1. The upper-level controller gives the active and reactive power reference commands $P_{\text {ref }}$ and $Q_{\text {ref }}$ through the MCU to the converter. The mid-level controller decouples the active and reactive power output. The lower-level controller produces sinusoidal pulse width modulation (SPWM) signals to IGBTs of the current source converter (CSC).

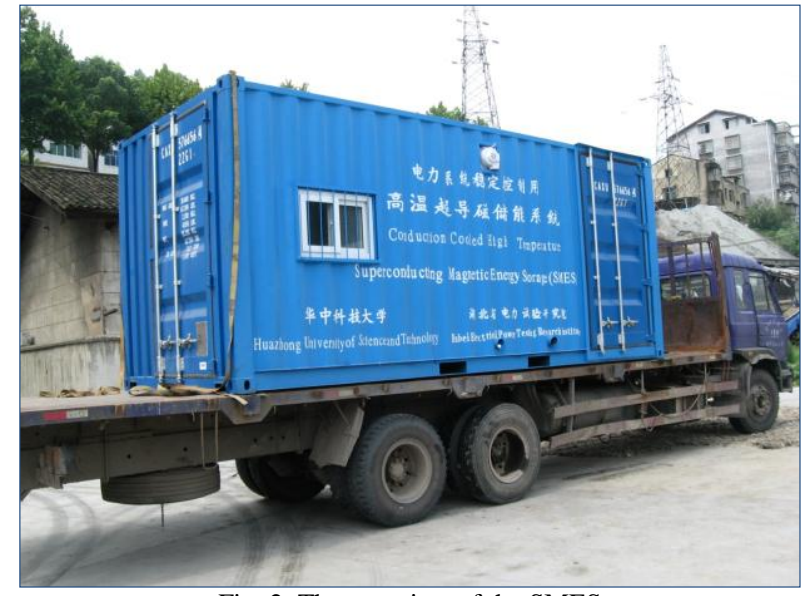

Fig. 2. The overview of the SMES

The SMES is assembled in a special water proof container with air conditioner installed. The container is $6 \mathrm{~m}$ long, $2.4 \mathrm{~m}$ wide and $2.6 \mathrm{~m}$ tall, as shown in Fig. 2. For the convenience of operation, the container has three doors and two windows. An air conditioner and fan are installed on the walls of the container with the thermal insulating layer. Some of the channel steels are installed on the inside surface of the container to improve its strength. The doors and windows, the fan, the air conditioner, as well as the external electrical and circulating water interfaces, are specially designed with water and wind proof feature so that the SMES may be used outdoors. During a 2-week field test, the SMES is kept working outdoors in hot summer and suffering thunderstorms, which demonstrates the well-design of the container.

The MCU, converter, cryogenic unit are in standard cabinets directly welded onto the top and the bottom of the container by channel steels. Because the magnet is a sophisticated device with pool capability of anti-shock and weight up to 1 ton, special care needs to be taken during transportation. Fig. 3 depicts the fixing of the dewar to the container. Tensioned springs are used to fix the dewar to the wall of the container and absorb horizontal impacts in transit. Vertically, suspension and base guarantee a smooth passage over the bumpiest road.

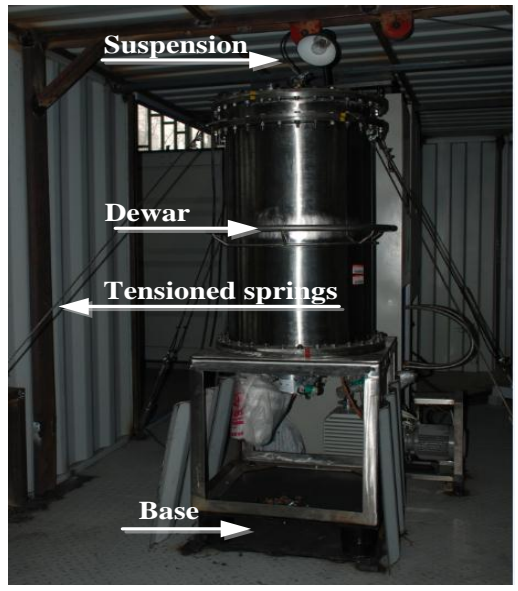

Fig. 3. The fixing of the dewar to the cabinet

Inside the dewar, between the upper flange of the vacuum vessel and its body, a connection flange is added and the magnet is hanged from it by four hanger rods, as shown in Fig. 4. The upper of the radiation shield is positioned by locating blocks to avoid its right-and-left displacement, and the underside is fixed by leg stays. Since the middle connection of the magnet is incompact and four screw arbors are too thin to resist shearing stress, four fixtures are added to connect the bottom flange of the magnet and the epoxy supporting plate, also the stay bolts are lengthened and locked on the supporting plate by locknuts. In order to prevent the swing of the bracing rods of the magnet, their footpads are fixed doubly by alignment pins and set bolts.

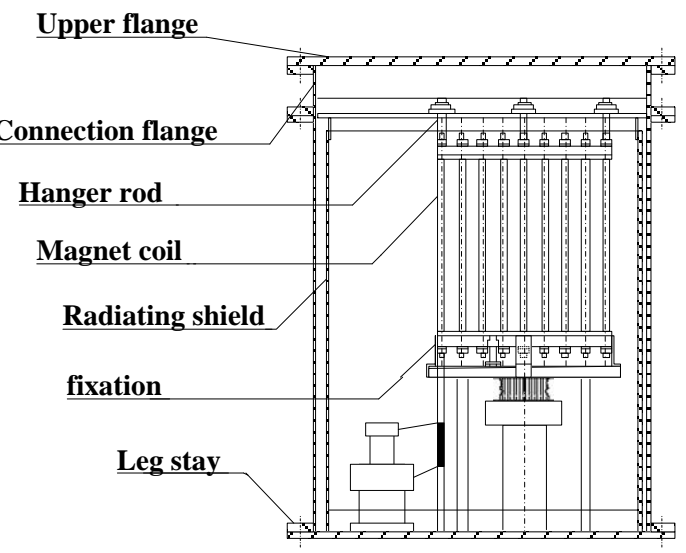

Fig. 4. The schematic of magnet inside the dewar

The field test of the SMES has been carried out in the 
Laohukou hydro power plant in Hubei province. The plant is $500 \mathrm{~km}$ from Huazhong University of Science and Technology where the SMES is manufactured. After travelling all the way the SMES is still workable. The movability feature of SMES is demonstrated by transporting the system under various road conditions.

\section{LABORATORY EXPERIMENTS OF THE SMES}

In order to demonstrate the effectiveness of the cryogenic unit, the converter, and the MCU, three aspects of laboratory experiments are carried out respectively, including heat characteristic analysis of the conduction cooling system, power regulation characters, and power oscillation damping.

\section{A. Cooling process of the superconducting magnet}

The magnet of the developed SMES consists of $32 \mathrm{Bi}$ 2223/Ag tapes, and designed as solenoid type according to the capacity of the magnet, the requirements of power regulation and the conduction-cool cryogenic unit [22]. The tape can operate with $3 \mathrm{~T}$ at $20 \mathrm{~K}$. Therefore, the magnet can operate with fast current ramps, which is important for dynamic power compensation [23]. The specifications are given in the appendix. The current leads are divided into two sections: one working in superconductive state which is made of $\mathrm{Bi}-2223$ sticks while the other works in the room temperature which is made of copper for interface with the outer environment.

The HTS is confined in a vacuum dewar for heat insulation. Conduction cooling method is adopted. The internal pressure of the dewar is $1.0 \times 10^{-1} \mathrm{~Pa}$. A radiation shield is installed inside. The cooling system consists of a single-stage GM cryocooler and a two-stage GM cryo-cooler. The operating temperature of the high temperature magnet and the current leads reaches the heat-equilibrium state, under a temperature varying from $16 \mathrm{~K}$ to $20 \mathrm{~K}$.

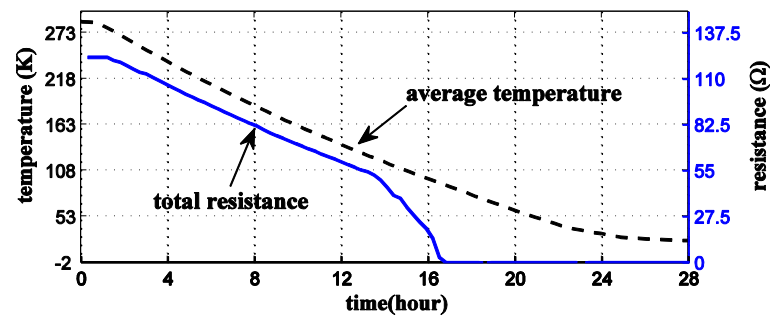

Fig. 5. Temperature and resistance variations of the superconductive magnet during cooling process

The variation of the magnet resistance and average temperature during the process of cooling down is shown in Fig. 5. It takes $17 \mathrm{~h}$ to cool the magnet to the superconducting state and $28 \mathrm{~h}$ to reach thermal equilibrium. Temperatures of the upper, middle and lower parts of the magnet are $25.6 \mathrm{~K}$, $20.5 \mathrm{~K}$ and $23 \mathrm{~K}$, respectively. These are the average temperatures of a variety of sensors which have different distances to the cooling head of the refrigerator. In fact, different part of the magnet reaches superconducting state at a different time. As the result, one cannot see the step change of the resistance to zero in the figure.

\section{B. Power regulation tests}

The converter is the electrical interface between the HTS at dc side and the ac power system. It is designed with a multimodule topology, which enables the scale of the SMES to be easily enlarged by connecting more magnets. Therefore, a number of small-scale SMES can be collectively controlled as a larger scale one [24]. The power electronic circuit is shown in Fig. 6. Four 6-bridge CSCs are directly connected in parallel at the ac side. The dc sides of the converter modules are paralleled through current-sharing inductance which limits the circulating current caused by inconsistence of instantaneous voltage. Each inductor is $15 \mathrm{mH}$ with resistance of less than $30 \mathrm{~m} \Omega$. There is also a filter circuit at the ac side of each converter. The single phase filter capacitance is $50 \mu \mathrm{F}$ for one converter module. The current and voltage of the dc side are rated to $200 \mathrm{~A}$ and $250 \mathrm{~V}$, respectively. The multimodule converter can be connected with a number of modules to gain the advantages of low-harmonic ac current and high total power capacity.

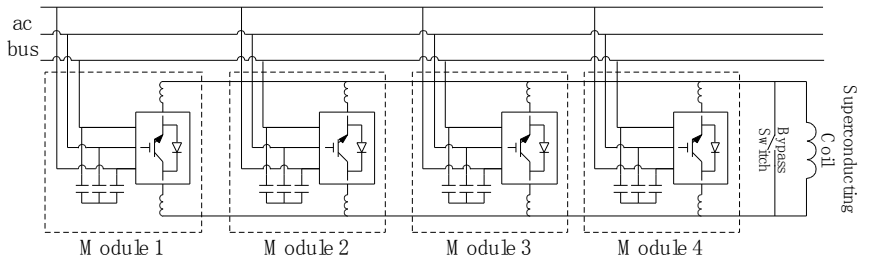

Fig. 6. The circuit diagram of the power conditioning subsystem

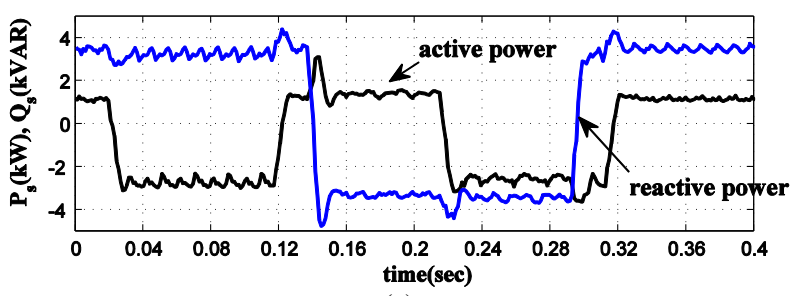

(a)

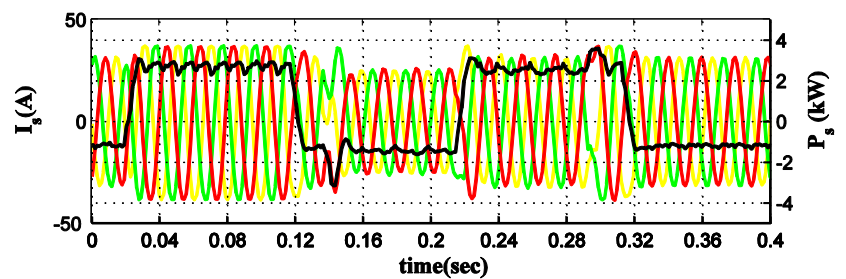

(b)

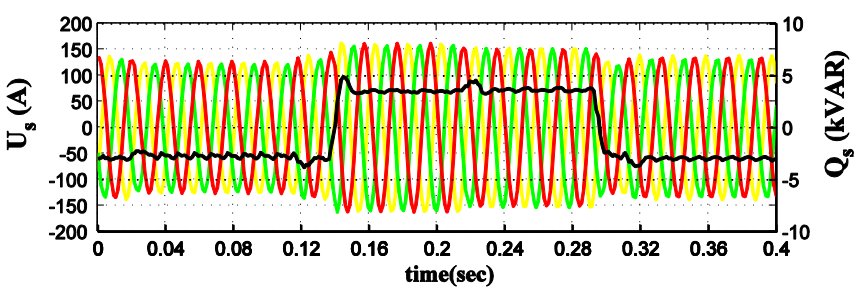

(c)

Fig. 7. Power regulation characteristics of SMES. (a) 4-quadrant power regulation.(b) Active power regulation.(c) Reactive power regulation.

The MCU consists of three major parts: the human machine interface, the measure and control unit and the waveform recording unit. It is used to monitor the real-time operation condition of both the SMES and the connected power system and send instructions to the converter through RS232 serial 
communication port according to the system requirements and control scheme.

The power regulation tests are carried out to demonstrate that SMES can regulate active and reactive power independently in 4 quadrants. Controlled by the open-loop controller in the MCU, the SMES follows the changing power regulation references. In Fig. 7(a), the active power reference changes between $+1 \mathrm{~kW}$ and $-2 \mathrm{~kW}$ in every $100 \mathrm{~ms}$, while the reactive power reference changes between $\pm 3 \mathrm{kV}$ ar in every $160 \mathrm{~ms}$. The results demonstrate that the SMES enables to decouple the active and reactive power. Fig. 7(b) and (c) show the active power and 3-phase current $I_{\mathrm{s}}$ injection, and reactive power and voltage at the terminal $U_{\mathrm{s}}$ of the SMES. From these figures one can see the proposed SMES has a response time less than half a cycle $(50 \mathrm{~Hz})$.

\section{Power oscillation damping}

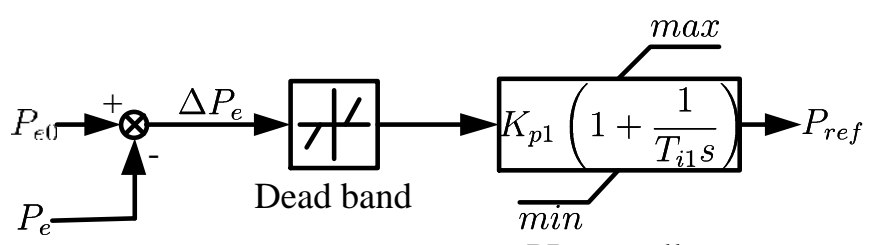

PI controller

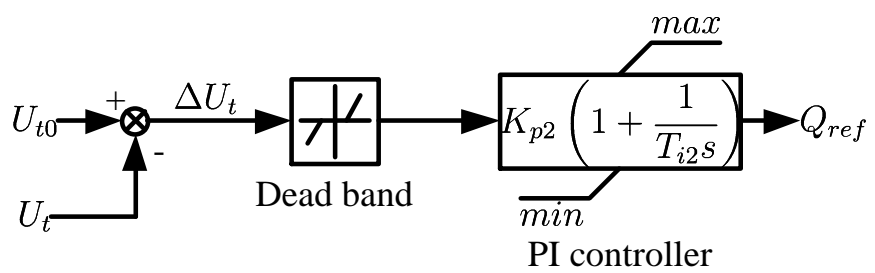

Fig. 8. The damping controller of SMES

The upper-level controller, embedded in the MCU, consists of two control loops for active and reactive power as shown in Fig. 8. One adopts the active power deviation, $\Delta P_{\mathrm{e}}$ as the input while the other adopts the voltage deviation as the input. Dead bands are set to $0.1 \mathrm{~kW}$ and $10 \mathrm{~V}$, respectively.

For the simplicity of a plug and play device, the bias of active power, $\Delta P_{\mathrm{e}}$ instead of the rotor speed derivation, $\Delta \omega$, is adopted as the feedback signal of the upper level controller. In the field test of the $30 \mathrm{~kJ}$ SMES system in the hydro power plant of Kyushu Electric Power Co., the $\Delta \omega$ control mode [25] is used for system stabilization. The rotor speed derivation, however, is usually hard to measure in power systems. In this work, the SMES is connected to the terminal of the generator. So the local signals such as the derivation of electrical power of the generator output is measured and used as the feedback signal for the upper level controller.

The dynamic experiment of the SMES for improving power system stability is carried out. A single machine infinite bus (SMIB) system with the SMES as shown in Fig. 9 is configured. The specifications are listed in the appendix. In the first experiment, the line 1 is tripped during a steady state. Fig. 10 illustrates the power oscillation with and without the SMES. Comparing the dotted and solid lines, one can see that the power oscillation is dampened and the system stability is improved by the SMES.

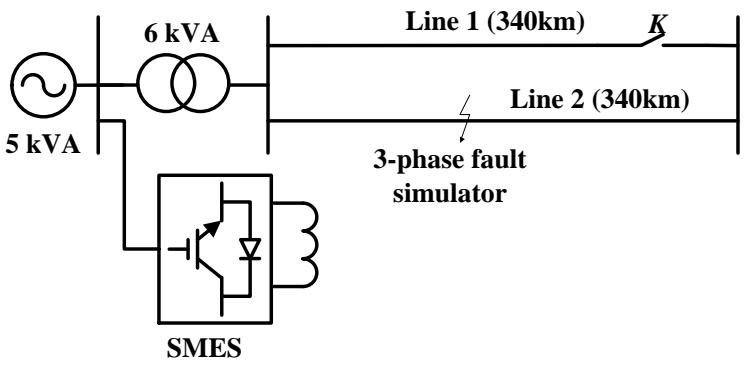

Fig. 9. Laboratory test system

The response of the SMES to a three-phase short circuit is studied in the second case where the three-phase short circuit fault occurs at the middle of line 2, lasting for $300 \mathrm{~ms}$. The fault is emulated by three-phase relay in the laboratory whose reclosure angle can be controlled accurately. Since line 1 has been out of service before the fault, this disturbance causes much more severe power oscillation. Fig. 11 depicts the process. Due to the very low voltage at the generator terminal where SMES is connected, the power chasing control scheme of the SMES, extracting or absorbing active power during a fault, can easily trigger the over-current protection of the CSC. The SMES resumes the system stability control when the generator's terminal voltage recovers to $90 \%$ of the nominal value according to MCU's measurement. Therefore, during $0.2 \mathrm{~s}$ to $0.4 \mathrm{~s}$, the dotted and solid lines coincide. After the time of $0.4 \mathrm{~s}$, dynamic stability of the ac power system is enhanced by the SMES as shown in Fig. 11 (b) to (e).

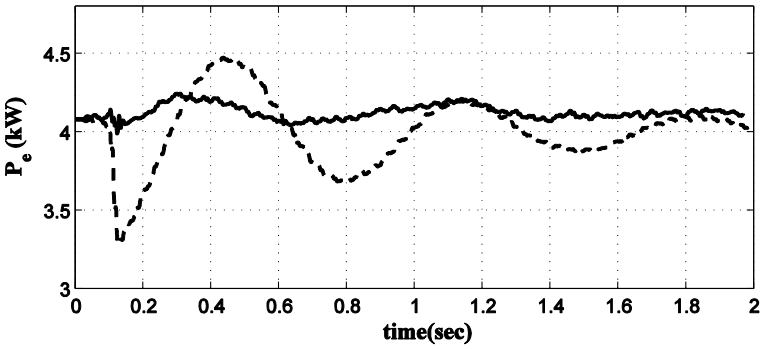

Fig. 10. Generator power swing with (solid line) and without (dash line) SMES in the first POD experiment

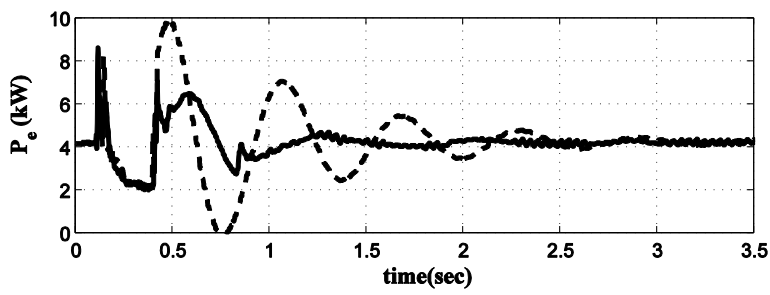

(a) Active power oscillation of the generator with (solid line) and without (dash line) SMES

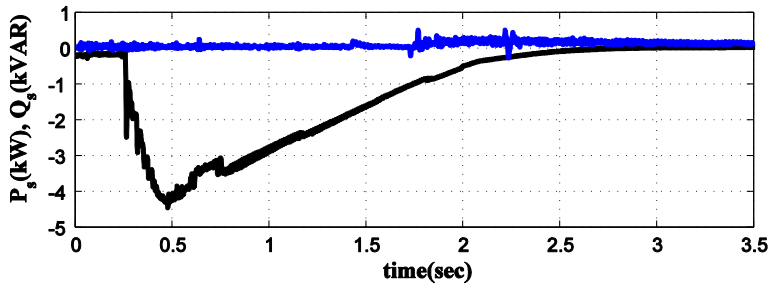

(b) Active (in black) and reactive (in blue) power output of SMES 


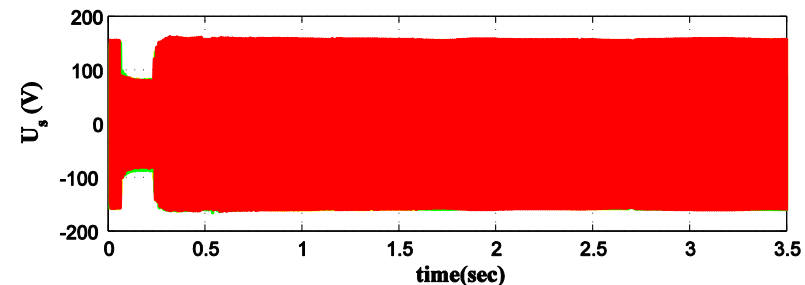

(c) 3-phase voltage at ac side of converter

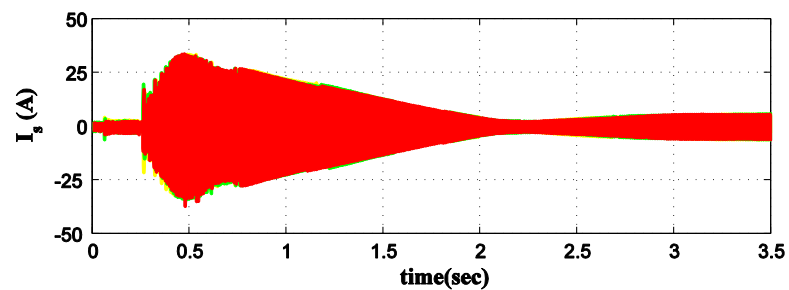

(d) 3-phase current injection of SMES

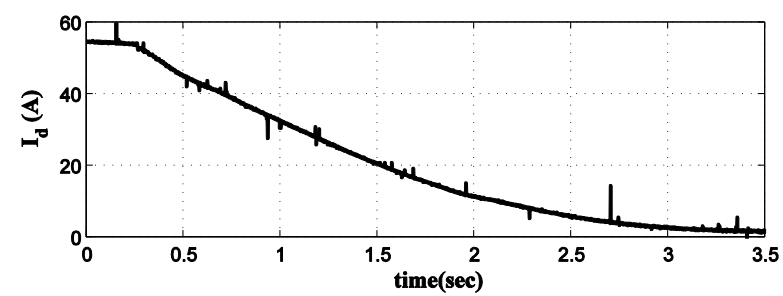

(e) Dc current

Fig. 11. Dynamic system response under 3-phase fault

\section{FIELD TEST OF SMES}

The field test of the SMES has been carried out in the Laohukou hydro power plant in Hubei province. Fig. 12 shows the power system for the field experiment, the generator is connected to the nearest substation through a $1.7 \mathrm{~km} 10 \mathrm{kV}$ transmission line. $T_{5}$ and $T_{6}$, being the same type of transformers as the step-up transformer $T_{4}$, are added to provide the suitable total inductance between the generator and the substation, which makes the system weaker so that the power oscillation can be observed more apparently. Disturbance is created by suddenly closing the circuit breaker to connect a $45 \mathrm{~kW}$ resistance load between $T_{5}$ and $T_{6}$ as shown in Fig. 12.

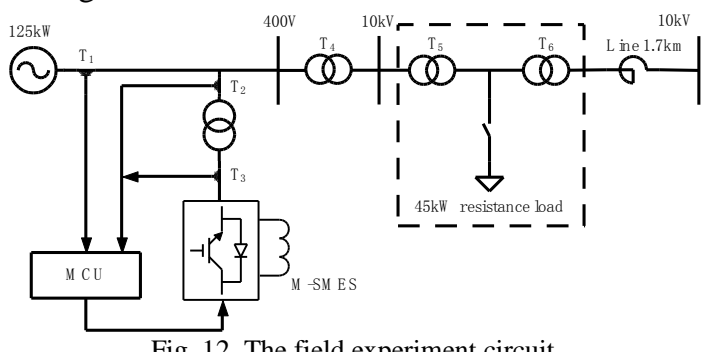

Fig. 12. The field experiment circuit

Fig. 13 depicts the power swing caused by the load disturbance. At $0.1 \mathrm{~s}$, the circuit breaker is closed. From Fig. 13 (a) and (b), one can see that the resistance load mainly causes active power oscillation, while has little impact on the generator's terminal voltage or reactive power output. In Fig. 13 (c), the generator terminal voltage stays at a relatively stable value in comparison with the current output. So the SMES effectively dampens the power oscillation with active power injection, the reactive power output remains zero.

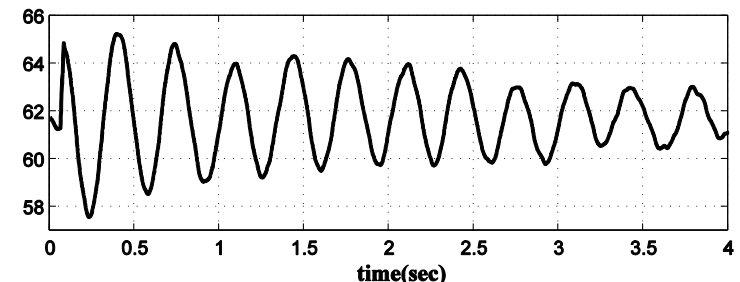

(a)

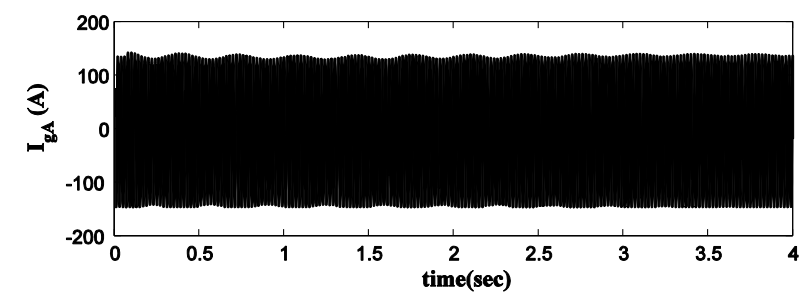

(b)

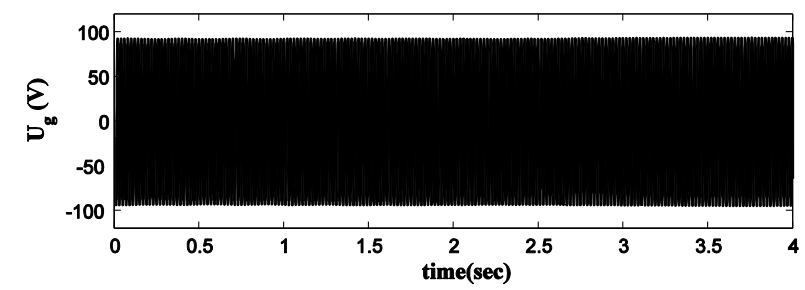

(c)

Fig. 13. Power oscillation caused by resistance load disturbance. (a) Generator real power output. (b) 1-phase current. (c) Generator terminal voltage.

Since the SMES has a relatively small capacity, the 125 $\mathrm{kW}$ generator is adjusted to operate at a low power production of $9 \mathrm{~kW}$. The SMES is set to output active power only. From Fig. 14, one can see that the power oscillation caused by 45 $\mathrm{kW}$ disturbance is suppressed by the SMES effectively.

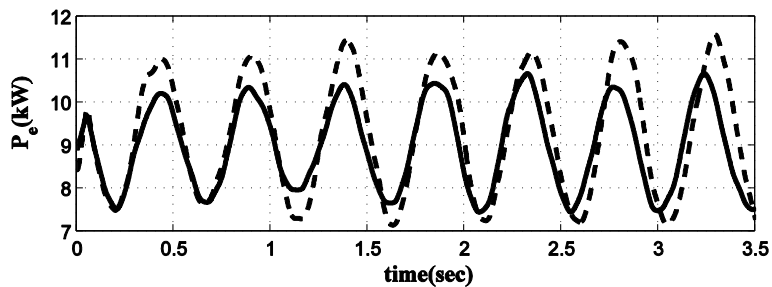

(a)

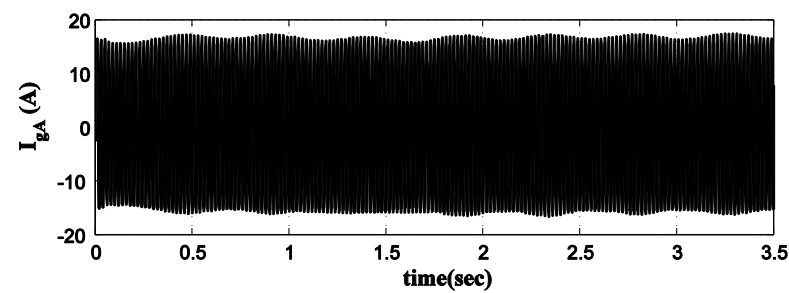

(b)

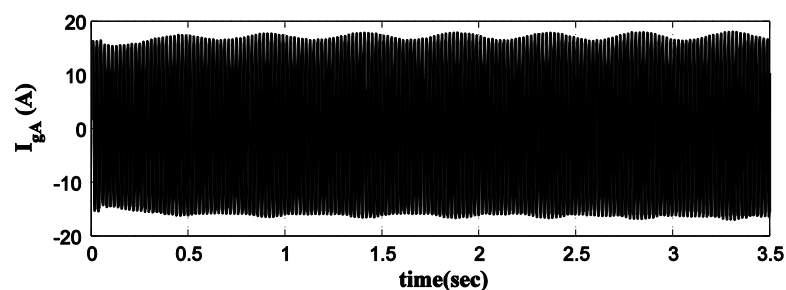

(c)

Fig. 14. Field test results, generator at the working point of 10kW. (a) Power oscillation with (solid line) and without (dash line) SMES. (b) 1 phase generator current with SMES. (c) 1 phase generator current without SMES 


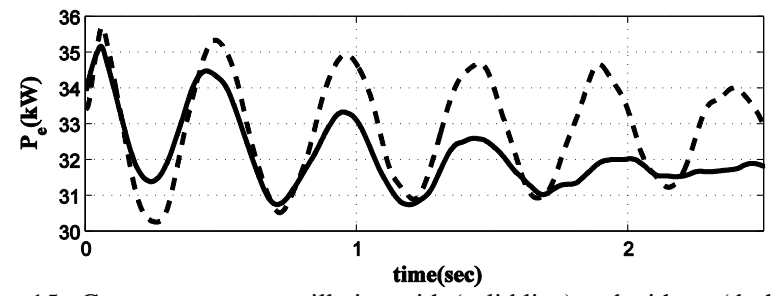

Fig. 15. Generator power oscillation with (solid line) and without (dash line) SMES at the working point of $33.5 \mathrm{~kW}$.

Another test is conducted the same as the last one, but the generator output is adjusted to $33.5 \mathrm{~kW}$. Fig. 15 shows the active power fluctuation of the generator. The SMES achieves best damping effect in this test and stabilized the generator in 4 swings. The fluctuation continues more than 6 cycles without SMES.

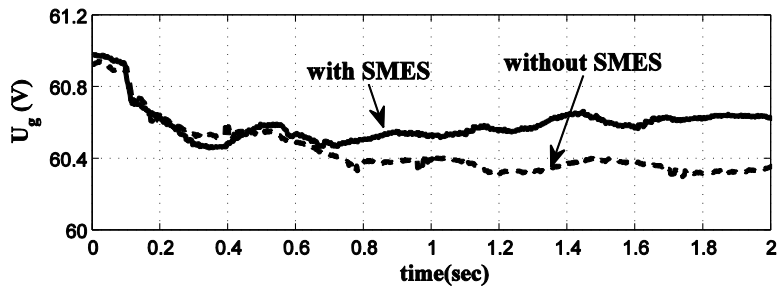

Fig. 16. The RMS voltage at the terminal of the generator

Another purpose of the field test is to verify that the SMES's ability of improving power quality. Laohukou hydro power plant is located at the end of the power system with severe voltage fluctuations. In this test, the test circuit remains the same as Fig. 12, but the generator stops running. Only the SMES is connected to low-side of $T_{4}$ directly. When $45 \mathrm{~kW}$ load is suddenly connected, the bus voltage drops, as shown by the dotted lines in Fig. 16. The SMES is activated after $500 \mathrm{~ms}$ to boost the bus voltage. Although the SMES has a limited capacity compared to the generator and system, and the bus voltage is difficult to return to the steady-state value, it is apparent that the SMES improves the voltage and restored it closer to the steady-state value.

\section{CONCLUSION}

A movable high temperature conduction-cooled SMES is built for applying SMES technology in power system applications. The movable SMES is flexible and easy for connection. The field test results show that the SMES has the feature of anti-shock design and workable under various conditions. It has the functions of energy storage, decoupled regulation of active and reactive power, power oscillation damping, as well as power quality improvement. As a new application for power system stability enhancement, the proposed SMES can facilitate the location and control strategy studies in future work.

\section{APPENDIX}

Specifications of the HTS are shown in Table I.
TABLE I SPECIFICATIONS OF THE SUPERCONDUCTING COIL

\begin{tabular}{cc} 
Specification & Parameter \\
\hline Coil configuration & Solenoid type \\
Conductors & Bi2223/Ag \\
Number of pancakes & 32 \\
Total conductor length & $7400 \mathrm{~m}$ \\
Inductance & $7.8 \mathrm{H}$ \\
Rated current & $100 \mathrm{~A}$ \\
Maximum field & 3 Tesla \\
\hline
\end{tabular}

Parameters of the generator for laboratory test are listed in Table II. The line reactance of the transmission line and the transformer at the generator side are $x_{l l}=x_{l 2}=0.89$ p.u. and $x_{\mathrm{T}}=0.13$ p.u.

\begin{tabular}{cc} 
TABLE II GENERATOR DATA IN LABORATORY TEST \\
\hline Specification & Parameter \\
\hline Power rating & $4 \mathrm{~kW} / 5 \mathrm{kVA}$ \\
Rated voltage & $210 \mathrm{~V}$ \\
Rated power factor cos $\varphi$ & 0.8 \\
direct-axis transient reactance & 0.126 p.u. \\
\hline
\end{tabular}

In the field test, the parameters of the generator with exciter are listed in Table III. The $10 \mathrm{kV}$ transmission line is 1.7 kilometers long. The capacity of the resistance load is $45 \mathrm{~kW}$.

\begin{tabular}{cc} 
TABLE III GENERATOR DATA IN FIELD TEST \\
\hline Specification & Parameter \\
\hline Power rating & $125 \mathrm{~kW} / 160 \mathrm{kVA}$ \\
Voltage & $400 \mathrm{~V}$ \\
Power factor $\cos \varphi$ & 0.8 \\
Exciter Current & $113 \mathrm{~A}$ \\
Exciter Voltage & $26.5 \mathrm{~V}$ \\
\hline
\end{tabular}

\section{Reference}

[1] W. Hassenzahl, "Superconducting magnetic energy storage," IEEE Trans. Magn., vol.25 no.2, pp. 750-758, Mar. 1989.

[2] I. Ngamroo, "Simultaneous Optimization of SMES Coil Size and Control Parameters for Robust Power System Stabilization," IEEE Trans. Appl. Supercond., vol.21 no.99, pp. 1358-1362, Jun. 2011.

[3] J. Zhu, Q. Cheng, B. Yang, W. Yuan, T. A. Coombs and M. Qiu, "Experimental Research on Dynamic Voltage Sag Compensation Using 2G HTS SMES," IEEE Trans. Appl. Supercond., vol.21 no.3, pp. 21262130, Jun. 2011

[4] M. G. Molina, P. E. Mercado and E. H. Watanabe, "Improved Superconducting Magnetic Energy Storage (SMES) Controller for HighPower Utility Applications," IEEE Trans. Energy Convers., vol.26 no.2, pp. 444-456, Jun. 2011.

[5] J. Shi, Y. Tang, K. Yang, L. Chen, L. Ren, J. Li and S. Cheng, "SMES based dynamic voltage restorer for voltage fluctuations compensation," IEEE Trans. Appl. Supercond., vol.20 no.3, pp. 1360-1364, Jun. 2010.

[6] J. Rogers, H. Boenig, R. Schermer and J. Hauer, "Operation of the 30 MJ superconducting magnetic energy storage system in the Bonneville Power Administration electrical grid," IEEE Trans. Magn., vol.21 no.2, 
pp. 752-755, Mar. 1985

[7] H. J. Boenig and J. F. Hauer, "Commissioning Tests Of The Bonneville Power Administration 30 MJ Superconducting Magnetic Energy Storage Unit," IEEE Transactions on Power Apparatus and Systems, vol.PAS104 no.2, pp. 302-312, Feb. 1985.

[8] R. Schermer, H. Boenig and J. Dean, "30 MJ superconducting magnetic energy storage for BPA transmission line stabilizer," IEEE Trans. Magn. vol.17 no.5, pp. 1950-1953, Sep. 1981.

[9] J. F. Hauer and H. J. Boenig, "Control Aspects of the Tacoma Superconducting Magnetic Energy Storage Project," IEEE Trans. Power Syst., vol.2 no.2, pp. 443-450, May 1987.

[10] M. Ross, M. Borodulin and Y. Kazachkov, "Using D-SMES devices to improve the voltage stability of a transmission system," presented at the IEEE PES Transmission and Distribution Conf. and Expo. (TDCE2001), Atlanta, US,

[11] A. Friedman, N. Shaked, E. Perel, F. Gartzman, M. Sinvani, Y. Wolfus, D. Kottick, J. Furman and Y. Yeshurun, "HT-SMES operating at liquid nitrogen temperatures for electric power quality improvement demonstrating," IEEE Trans. Appl. Supercond., vol.13 no.2, pp. 18751878, Jun. 2003.

[12] R. Kreutz, H. Salbert, D. Krischel, A. Hobl, C. Radermacher, N. Blacha, P. Behrens and K. Dutsch, "Design of a $150 \mathrm{~kJ}$ high-Tc SMES (HSMES) for a $20 \mathrm{kVA}$ uninterruptible power supply system," IEEE Trans. Appl. Supercond., vol.13 no.2, pp. 1860-1862, Jun. 2003.

[13] P. Tixador, B. Bellin, M. Deleglise, J. C. Vallier, C. E. Bruzek, S. Pavard and J. M. Saugrain, "Design of a $800 \mathrm{~kJ}$ HTS SMES," IEEE Trans. Appl. Supercond., vol.15 no.2, pp. 1907-1910, Jun. 2005.

[14] K. Shikimachi, H. Moriguchi, N. Hirano, S. Nagaya, T. Ito, J. Inagaki, S. Hanai, M. Takahashi and T. Kurusu, "Development of MVA class HTS SMES system for bridging instantaneous voltage dips," IEEE Trans. Appl. Supercond., vol.15 no.2, pp. 1931-1934, Jun. 2005.

[15] H. Hayashi, T. Nagafuchi, Y. Hatabe, K. Takeuchi, M. Arika, I. Kawashima, K. Terazono, S. Koso and H. Osaki, "Development of costreduction SMES for power system stabilization," Journal of the Cryogenic Society of Japan, vol.40 no.5, pp. 167-174, 2005.

[16] H. Hayashi, Y. Hatabe, T. Nagafuchi, A. Taguchi, K. Terazono, T. Ishii and S. Taniguchi, "Test results of power system control by experimental SMES," IEEE Trans. Appl. Supercond., vol.16 no.2, pp. 598-601, 2006.

[17] N. Taesik, W. S. Jae and H. Kyeon, "The Beneficial Role of SMES Coil in DC Lines as an Energy Buffer for Integrating Large Scale Wind Power," IEEE Trans. Appl. Supercond., vol.22 no.3, pp. 1-4, Jun. 2012.

[18] S. Nomura, N. Tanaka, K. Tsuboi, H. Tsutsui, S. Tsuji lio and R. Shimada, "Design considerations for SMES systems applied to HVDC links," in 13th European Conf. Power Electronics and Applications (EPE 2009), pp. 1-10.

[19] L. Ren, Y. Tang, J. Li, Z. Li, L. Chen, J. Chen, J. Shi and J. Wen, "Conduction-cooled YBCO HTS current lead for SMES application," IEEE Trans. Appl. Supercond., vol.20 no.3, pp. 1737-1740, Jun. 2010.

[20] J. Cerulli, G. Melotte and S. Peele, "Operational experience with a superconducting magnetic energy storage device at Owens Corning Vinyl Operations, Fair Bluff, North Carolina," presented at the Power Engineering Society Summer Meeting (PESGM),

[21] J. Shi, Y. Tang, Y. Zhou, J. Chen, D. Xu, H. Wang, Y. Lu, L. Ren, B. Wei, J. Li and S. Cheng, "Development of a conduction-cooled HTS SMES," IEEE Trans. Appl. Supercond., vol.17 no.3, pp. 3846-3851, Sep. 2007.

[22] T. Dai, J. Li, Y. Tang, Y. Zhou, S. Chen and Y. Pan, "Thermal analysis of a conduction-cooled HTS coil with heat disturbances," IEEE Trans. Appl. Supercond., vol.15 no.2, pp. 1679-1682, Jun. 2005.

[23] T. Dai, Z. Fan, J. Li, Y. Tang, S. Cheng, Y. Pan and J. Wang, "Design study on $50 \mathrm{~kJ}$ HTS SMES for simulated dynamic experiment of electric power systems," vol.412-414 no.2004, pp. 1239-1243, May 2004.

[24] J. Li, K. W. E. Cheng, D. Sutanto and D. Xu, "A multi-module hybrid converter for high-temperature superconducting magnetic energy storage systems (HT-SMES)," IEEE Trans. Power Del., vol.20 no.1, pp. 475480, Jan. 2005.

[25] F. Irie, M. Takeo, S. Sato, O. Katahira, F. Fukui, H. Okada, T. Ezaki, K. Ogawa, H. Koba, M. Takamatsu and T. Shimojo, "A field experiment on power line stabilization by a SMES system," IEEE Trans. Magn., vol.28 no.1, pp. 426-429, Jan. 1992.
Jiakun Fang received the Ph.D. degree from Huazhong University of Science and Technology (HUST), Wuhan, China in 2012. Currently he is a post-doc researcher in Department of Energy Technology, Aalborg University, Denmark. His research interests include power system dynamic stability control and power grid complexity analysis.

Jinyu Wen received the B.Eng. and Ph.D. degrees all in electrical engineering from Huazhong University of Science and Technology (HUST), Wuhan, China, in 1992 and 1998, respectively. He was a visiting student from 1996 to 1997 and research scholar from 2002 to 2003, all at the University of Liverpool UK. In 2003 he joined the HUST and now is a professor at HUST. His current research interests include smart grid, renewable energy, energy storage, FACTS, HVDC and power system operation and control.

Jing Shi was born in China in 1980. She received her Ph.D. degree from Huazhong University of Science and Technology (HUST), Wuhan, China She is currently working on the characteristic analysis of the superconducting power systems, especially the characteristic analysis of the superconducting magnetic energy storage system.

Li Ren received the B.S and M.S. degrees from Huazhong University of Science and Technology, Wuhan, China, in 1990 and 2004, respectively. She is currently working as an associate professor at Huazhong University of Science and Technology, specializing in applied superconductivity technology.

Yuejin Tang received the B.S. and M.S. degrees from Huazhong University of Science and Technology (HUST), Wuhan, China, in 1982 and 1984, respectively, majoring in high voltage engineering. He received the Ph.D. degree in engineering from Nagoya University, Japan, in 1996, majoring in applied superconductivity. He is a professor at HUST and his work presently concerns applied superconductivity and high-voltage technology.

Xiaotao Peng is now working as an associate professor in Department of Electrical Power engineering, Wuhan University. He received his Ph.D. degree from Huazhong University of Science and Technology (HUST), China, in 2006. In recent years, he has been engaged in the areas of stabilization control of power system and superconducting power science and technology.

Zhe Chen (M'95, SM'98) received the B.Eng. and M.Sc. degrees from Northeast China Institute of Electric Power Engineering, Jilin City, China, and the Ph.D. degree from University of Durham, U.K. Currently is a full Professor with the Department of Energy Technology, Aalborg University, Denmark. 